\title{
The Histopathological Classification of ANCA-associated Glomerulonephritis Comes of Age
}
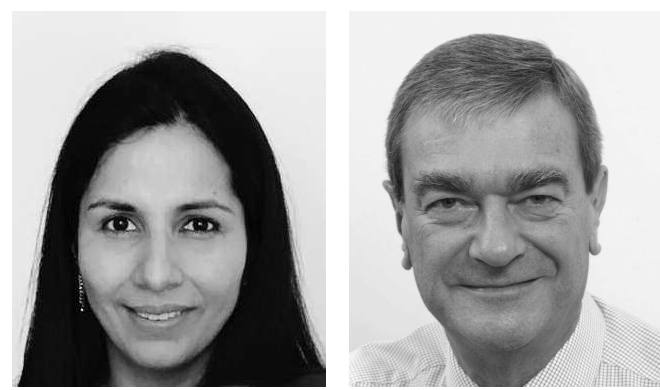

The antineutrophil cytoplasm antibody (ANCA)-associated vasculitides (AAV) are multisystem disorders characterized by necrotizing inflammation of blood vessels, and are associated with an untreated mortality of around $90 \%{ }^{1}$. These disorders include granulomatosis with polyangiitis (GPA), microscopic polyangiitis (MPA), eosinophilic granulomatosis with polyangiitis (EGPA), and renal limited vasculitis $(\mathrm{RLV})^{2}$.

Renal manifestations of AAV, which commonly include rapidly progressive glomerulonephritis, result in endstage renal failure or death in $40 \%$ of patients ${ }^{3}$. Despite the introduction of newer biological therapies, treatment continues to cause significant morbidity and mortality, and has been associated with more deaths at 1 year than the disease process itself $^{4}$. A major challenge in the management of patients with renal AAV remains the identification of factors, both clinical and histopathological, which are predictive of response to therapy, risk of relapse, and renal and patient survival. Recognition of such factors would aid the implementation of patient-tailored therapy.

Clinical factors that have been demonstrated to correlate with the prognosis of renal AAV include age, with increasing age correlating with poorer outcome; and presenting creatinine, with a better prognosis in patients presenting with a lower serum creatinine ${ }^{5}$. These clinical factors cannot, however, be considered in isolation. The "gold standard" for diagnosis of renal AAV remains the renal biopsy. A number of histopathological factors have been reported to correlate with renal prognosis 6 . A higher percentage of normal glomeruli has been well established as being predictive of better renal outcome $e^{6,7}$. A greater percentage of cellular crescents has been reported as predictive of a better response to therapy ${ }^{7}$. Increasing percentage of tubular atrophy and glomerular sclerosis have been associated with poorer renal outcomes ${ }^{7}$.

In 2010, an international working group of renal pathologists proposed a histological classification for renal AAV based on these findings. This classification divides patient biopsies into 4 classes: focal (>50\% normal glomeruli), crescentic ( $>50 \%$ cellular crescents), sclerotic ( $>50 \%$ sclerotic glomeruli), and mixed (any other combination) ${ }^{8}$. A validation study was carried out using the biopsies of 100 patients enrolled in various European Vasculitis Study Group trials $^{8}$. This confirmed the prognostic value of the classification system over a 1- and 5-year followup period, with patients in the focal class experiencing the best outcomes in terms of estimated glomerular filtration rate (eGFR) and renal survival followed in order by those in the crescentic, mixed, and sclerotic classes ${ }^{8}$.

A number of validation studies have since been published worldwide. These studies have varied in size and, to our knowledge, 7 studies have included over 100 biopsies $^{9,10,11,12,13,14,15,16}$. The first 6 of these studies have been summarized in publications by Rahmattulla, et $\mathrm{al}^{17}$ and van Daalen, et $a l^{18}$. The largest and most recent was carried out by Bjørneklett, et $a l^{16}$ in Norway, and included 250 patients with AAV. The study agreed with the general consensus that the classification is a useful predictor of renal outcome, with patients in the focal class experiencing the best and patients in the sclerotic class the worst renal outcomes ${ }^{16}$. There was no significant difference in renal outcome between the mixed and crescentic classes. Bjørneklett, et al also calculated the prognostic accuracy of the classification system using receiver-operator curve characteristics, and determined it to be of moderate quality ${ }^{16}$.

In this issue of The Journal ${ }^{19}$, Chen, et al report the results of their own validation study and in addition, the results of a metaanalysis they performed to assess the predictive values of the histopathological classification system. A retrospective analysis was carried out on 186 patients with ANCA-associated glomerulonephritis in Shanghai, China. As expected for this part of the world, the majority of patients $(154 ; 83 \%)$ had a diagnosis of MPA. There were 10 patients with GPA, 4 with EGPA, and 18 with

See Histopathologic classification in AAV, page 304

Personal non-commercial use only. The Journal of Rheumatology Copyright @ $~ 2017$. All rights reserved. 
RLV. Of the biopsies, $24.7 \%$ were classified as focal, $19.4 \%$ as crescentic, $19.4 \%$ as sclerotic, and the remainder (36.6\%) as mixed. Interestingly, the majority of patients in the study who were proteinase 3 (PR3)-ANCA-positive were included in the focal class. This is consistent with the recent publication from Cornec, et al, which reported less severe renal involvement in PR3-positive patients than those with MPO positivity $^{20}$.

Tubulointerstitial injury was also scored and assessed by class. Consistent with previous studies, the focal class had the least and the sclerotic class the most tubulointerstitial injury. There were statistically significant differences across the groups with regards to serum creatinine and proteinuria, with the lowest serum creatinine and level of proteinuria detected in patients in the focal class, followed by the crescentic, mixed, and sclerotic classes, respectively.

The best renal survival was in the focal class and the worst in the sclerotic class up to around 100 months. There was no significant difference in renal survival between the crescentic and mixed classes up to this timepoint. These findings are consistent with previous studies. At around 140 months, it seems from the survival curve that there was a poorer prognosis in the mixed than the sclerotic class; however, as discussed by the authors, this may be because of the longer followup of patients in the mixed class.

Patient survival by class at 1 year followed a similar pattern to that of renal survival, but this was lost on followup. The lack of a consistent relationship between class and patient survival is consistent with the literature, including the 250 patients in Bjørneklett, et al's study, for whom there was no difference in patient survival across the classes at 1 year ${ }^{16}$. This could be (as explained by the authors) due to the multifactorial characteristic of patient survival in $\mathrm{AAV}$, and the fact that morbidity and mortality cannot be solely attributable to renal involvement. In addition, worldwide differences in the efficiency of renal replacement therapy provided could contribute to variations in patient survival across the validation populations.

Chen, et al also carried out an interesting metaanalysis. With the varying numbers of patients in previous validation studies, and the difficulties of carrying out multivariate analysis on small numbers, combining the results and carrying out a metaanalysis of these studies was extremely useful. Their metaanalysis included 1601 patients from 16 different worldwide studies and confirmed the outcome in the different classes as per the 2010 classification, with the best outcome in the focal class, intermediate outcomes in the crescentic and mixed classes, and the worst outcome in the sclerotic class. Results were similar for both the Eastern and Western populations, with the implication that the classification can be applied across different ethnic groups.

As discussed by the authors of the paper, the study is limited by its retrospective design and variations between centers with regard to eGFR assessment, as well as the avail- ability of treatment data and Birmingham Vasculitis Activity Score. Despite these limitations, this is the second largest validation study and the only metaanalysis of the various validation studies, and adds much weight to the current literature.

The histopathological classification has truly come of age and become widely accepted in populations across the globe, especially for patients classified as focal or sclerotic. Because there are discrepancies as to whether mixed or crescentic classes have a better prognosis, and as outcomes are similar in many series, there is some argument to consider combining these 2 classes. Further prospective studies are needed to accurately assess the response to different types of treatment in the different classes, particularly the crescentic and mixed classes.

There are successful histopathological classification systems in clinical use for diabetic and immunoglobulin A nephropathy. Six years on from the initial proposal of the classification for renal AAV and many validation studies later, perhaps we are one step closer to achieving the goal of using the classification system together with clinical features to provide patients with a realistic prognosis and to tailor their therapy accordingly. This would represent a major advance in the management of this disorder.

ANISHA TANNA, MBBS, BSc,

Renal and Vascular Inflammation Section, Department of Medicine, Imperial College London,

Hammersmith Campus;

CHARLES D. PUSEY, DSc, FMedSci, Renal and Vascular Inflammation Section, Department of Medicine, Imperial College London, Hammersmith Campus.

Address correspondence to Prof. C.D. Pusey, Renal and Vascular Inflammation Section, Department of Medicine, Imperial College London, Hammersmith Campus, Du Cane Road, London W12 0NN, UK. E-mail: c.pusey@imperial.ac.uk

\section{REFERENCES}

1. Watts RA, Scott DG. Epidemiology of the vasculitides. Curr Opin Rheumatol 2003;15:11-6.

2. Jennette JC, Falk RJ, Bacon PA, Basu N, Cid MC, Ferrario F, et al 2012 revised International Chapel Hill Consensus Conference Nomenclature of Vasculitides. Arthritis Rheum 2013;65:1-11.

3. Booth AD, Almond MK, Burns A, Ellis P, Gaskin G, Neild GH, et al; Pan-Thames Renal Research Group. Outcome of ANCA-associated renal vasculitis: a 5-year retrospective study. Am J Kidney Dis 2003;41:776-84.

4. Little MA, Nightingale P, Verburgh CA, Hauser T, De Groot K, Savage C, et al; European Vasculitis Study (EUVAS) Group. Early mortality in systemic vasculitis: relative contribution of adverse events and active vasculitis. Ann Rheum Dis 2010;69:1036-43.

5. de Lind van Wijngaarden RA, Hauer HA, Wolterbeek R, Jayne DR, Gaskin G, Rasmussen N, et al. Clinical and histologic determinants of renal outcome in ANCA-associated vasculitis: a prospective analysis of 100 patients with severe renal involvement. J Am Soc Nephrol 2006;17:2264-74.

Personal non-commercial use only. The Journal of Rheumatology Copyright @ 2017 . All rights reserved. 
6. Bajema IM, Hagen EC, Hermans J, Noël LH, Waldherr R, Ferrario $\mathrm{F}$, et al. Kidney biopsy as a predictor for renal outcome in ANCA-associated necrotizing glomerulonephritis. Kidney Int 1999;56:1751-8.

7. Vergunst CE, van Gurp E, Hagen EC, van Houwelingen HC, Hauer HA, Noël LH, et al. An index for renal outcome in ANCA-associated glomerulonephritis. Am J Kidney Dis 2003;41:532-8

8. Berden AE, Ferrario F, Hagen EC, Jayne DR, Jennette JC, Joh K, et al. Histopathologic classification of ANCA-associated glomerulonephritis. J Am Soc Nephrol 2010;21:1628-36.

9. Iwakiri T, Fujimoto S, Kitagawa K, Furuichi K, Yamahana J, Matsuura Y, et al. Validation of a newly proposed histopathological classification in Japanese patients with anti-neutrophil cytoplasmic antibody-associated glomerulonephritis. BMC Nephrol 2013;14:125.

10. Chang DY, Wu LH, Liu G, Chen M, Kallenberg CG, Zhao MH. Re-evaluation of the histopathologic classification of ANCA-associated glomerulonephritis: a study of 121 patients in a single center. Nephrol Dial Transplant 2012;27:2343-9.

11. Hilhorst M, Wilde B, van Breda Vriesman P, van Paassen P, Cohen Tervaert JW; Limburg Renal Registry. Estimating renal survival using the ANCA-associated GN classification. J Am Soc Nephrol 2013;24:1371-5.

12. Ford SL, Polkinghorne KR, Longano A, Dowling J, Dayan S, Kerr PG, et al. Histopathologic and clinical predictors of kidney outcomes in ANCA-associated vasculitis. Am J Kidney Dis 2014;63;227-35.

13. Unlu M, Kiremitci S, Ensari A, Ozluk Y, Kilicaslan I, Ozdemir BH, et al. Pauci-immune necrotizing crescentic glomerulonephritis with crescentic and full moon extracapillary proliferation: clinico-pathologic correlation and follow-up study. Pathol Res Pract 2013;209;75-82.
14. Quintana LF, Peréz NS, De Sousa E, Rodas LM, Griffiths MH, Solé $\mathrm{M}$, et al. ANCA serotype and histopathological classification for the prediction of renal outcome in ANCA-associated glomerulonephritis. Nephrol Dial Transplant 2014;29:1764-9.

15. Tanna A, Guarino L, Tam FW, Rodriquez-Cubillo B, Levy JB, Cairns TD, et al. Long-term outcome of anti-neutrophil cytoplasm antibody-associated glomerulonephritis: evaluation of the international histological classification and other prognostic factors. Nephrol Dial Transplant 2015;30:1185-92.

16. Bjørneklett R, Sriskandarajah S, Bostad L. Prognostic value of histologic classification of ANCA-associated glomerulonephritis. Clin J Am Soc Nephrol 2016;11:2159-67.

17. Rahmattulla C, Bruijn JA, Bajema IM. Histopathological classification of antineutrophil cytoplasmic antibody associated glomerulonephritis: an update. Curr Opin Nephrol Hypertens 2014;23:224-31.

18. van Daalen E, Ferrario F, Noël LH, Waldherr R, Hagen EC, Bruijn JA, et al. Twenty-five years of RENHIS: a history of histopathological studies within EUVAS. Nephrol Dial Transplant 2015;30 Suppl 1:i31-6.

19. Chen YX, Xu J, Pan XX, Shen PY, Li X, Ren H, et al. Histopathological classification and renal outcome in patients with antineutrophil cytoplasmic antibodies-associated renal vasculitis: a study of 186 patients and metaanalysis. J Rheumatol 2017; 44:304-13.

20. Cornec D, Cornec-Le Gall E, Fervenza FC, Specks U. ANCA-associated vasculitis - clinical utility of using ANCA specificity to classify patients. Nat Rev Rheumatol 2016;12:570-9.

J Rheumatol 2017;44:265-7; doi:10.3899/jrheum.170006 